\title{
BENTUK SAPAAN BAHASA INGGRIS AMERIKA SEBAGAI STRATEGI DISKURSIF DALAM FILM PRODUKSI AMERIKA: SUATU KAJIAN PRAGMATIK
}

\author{
Eko W. Koeshandoyo \\ Fakultas Ilmu Budaya Unpad \\ ekoeshandoyo@yahoo.com
}

\begin{abstract}
Abstrak
Bentuk sapaan sering menjadi bagian dari sebuah interaksi verbal antara dua pelibat atau lebih. Pengunaan bentuk sapaan ternyata tidak semata-mata memiliki fungsi indeksikal saja namun juga memiliki fungsi strategi diskursif yang digunakan penggunanya untuk mencapai tujuan percakapan. Penelitian ini bertujuan meneliti apa saja fungsi bentuk sapaan bahasa Inggris Amerika sebagai strategi diskursif dalam percakapan. Penelitian ini menggunakan 8 film produksi Amerika yang menggunakan bahasa Inggris Amerika dengan latar kehidupan modern. Hasil penelitian menunjukan bahwa bentuk sapaan memiliki 10 fungsi strategi diskursif berupa pemenuhan aturan dan norma baku secara hukum, pematuhan aturan dan norma organisasional, penunjukan kesantunan, refleksi evaluatif personal atas jarak sosial dan solidaritas, penunjukan hubungan kekerabatan, penanda solidaritas dalam suatu kelompok sosial, strategi humoristik, penanda sifat formal-tidaknya pembicaraan, perujuk hubungan kuasa penyapa-pesapa, dan ekspresi mitigatif.
\end{abstract}

Kata Kunci: Bentuk sapaan, perbedaan kuasa, solidaritas, kesantunan, jarak sosial

\begin{abstract}
Address forms are often used in verbal interactions between two interlocutors or more. Apparently, the use of address forms fulfill their functions not only as indexicals but also as discursive strategies. This research is aimed at finding the functions of Address Forms in American English as discursive strategies in verbal interactions. This research uses 8 American-English films by American producers with modern settings. The results show that address forms serve 10 functions as discursive strategies to enable an interlocutor to conform to legal regulations or norms, comply with certain organisational regulations or norms, perform acts of politeness, express personal evaluation on social distance, refer to kinship systems, conform to common norms in a community or social groups as an act of solidarity, gain humorous effects, refer to addresser-addressee relative positions, and use them as mitigating device.
\end{abstract}

Keywords: address forms, power differentials, solidarity, politeness, social distance

\section{PENDAHULUAN}

Salah satu unsur bahasa yang menjadi perhatian kajian sosiolinguistik adalah Bentuk Sapaan (BS). Saat seseorang menyapa orang lain dengan menggunakan BS dalam kondisi normal, ia harus melakukan pilihan BS yang bergantung pada faktor-faktor seperti situasi, hubungan penyapa-pesapa atau tenor, maupun mungkin sekali perasaan atau kondisi emosi seseorang. Seseorang bernama Michael Brandt pada beberapa konteks dapat disapa dengan 'Professor Brandt', 'Dean Brandt', 'Mr. Brandt', 'Son', 'daddy', 'darling', 'grandpa', 'Michael', 'Mickey', 
bahkan julukan yang sifatnya menunjukkan keakraban. Agar tidak terjadi ketidaknyaman atau terganggunya hubungan sosial, tentu saja seseorang yang hendak menyapa Michael Brandt ini harus dapat memilih BS yang tepat. Sikap sosial dapat didefinisikan sebagai pernyataan apakah seseorang mematuhi norma sosial (conformity to social norms) atau tidak. Seseorang dapat menyatakan sikap atau perasaannya dengan memilih untuk mematuhi norma sosial yang berlaku tidak. Sikap ini salah satunya dapat ditunjukkan melalui cara menyapa atau menggunakan bentuk sapaan (BS).

Bentuk sapaan (BS) ini dalam bahasa Inggris ada yang menyebut Terms of address/address terms dan forms of address/address form. Meskipun demikian kedua istilah tersebut beserta variannya mengacu pada hal yang sama yaitu pada dasarnya suatu cara menyapa, memanggil, atau menarik perhatian lawan bicara. Dalam membicarakan masalah BS ini dikenal adanya 2 istilah linguistik yang berhubungan, yaitu vokatif dan deiksis.

Istilah vokatif yang berasal dari bahasa Latin vocaticus yang berarti 'kasus penamaan' (dari kata vocare yang berarti 'memanggil') pada awalnya adalah jenis kasus gramatika bahasa Latin yang berhubungan dengan penandaan BS secara morfologis pada nomina atau kata lainnya dan berkembang menjadi suatu bentuk gramatikal yang dapat berupa morfem, kata, atau frasa yang digunakan untuk menarik perhatian, memberikan signal pada orang yang sedang diajak bicara, atau menandai hubungan yang ada (McArthur, 1992:1093). Hal ini dapat dilihat pada contoh dalam bahasa Latin dari karya Shakespeare: Et tu, Brute? (and you, Brutus?). terlihat bahwa bahasa Latin memiliki kasus vokatif yang memberikan pemarkah pada nomina yang menjadi BS (Brute untuk Brutus). Bahasa Inggris tidak memberikan pemarkah khusus pada BS atau BS tetap dalam bentuk nominatif seperti "John, I want to talk to you" atau "I don't see it that way, John" (lihat juga Wales (1996)). Crystal (2003:220) mengatakan bahwa vokatif ini sejenis nama yang ditujukan pada seseorang atau orang yang diajak bicara yang mungkin berfungsi untuk mengundang perhatian atau menyatakan hubungan sosial tertentu atau sikap personal seperti pada

- Doctor, I need a tonic

- Leave it alone, imbecile!.

Ia juga berpendapat bahwa vokatif adalah suatu unsur kalimat yang sifatnya opsional atau dapat dipakai atau tidak dalam kalimat karena kehadirannya tidak mengubah konstruksi kalimat dan bukan unsur struktur klausa seperti subjek, objek, atau verba. Jadi masalah vokatif ini terkait erat dengan masalah atau berada pada tataran gramatika kalimat.

Dalam bidang pragmatik dikenal adanya istilah deiksis yang berasal bahasa Yunani yang berarti 'merujuk'. Deiksis ini dapat didefinisikan sebagai unsur bahasa yang digunakan untuk mengacu pada karakteristik situasi yang sifatnya personal, temporal, lokasional, maupun sosial (lihat Crystal (1983), Cruise (2000), dan Yule (2001). Ahli lainnya, Levinson (1999:132), mengatakan bahwa interpretasi atas suatu tindak verbal amat bergantung pada konteks terjadinya tindak tutur tersebut yang dapat memberikan informasi mengenai acuan orang, waktu, tempat, maupun kondisi sosial. Deiksis sendiri terdiri dari 4 jenis, yaitu deiksis persona, temporal, lokasional, dan sosial (lihat Levinson (1983), Crystal (1997, 2003), dan Yule (2000)). Yang berkaitan dengan BS terutama sekali adalah deiksis sosial. Deiksis sosial ini 
didefinisikan oleh Levinson $(1983 ; 89)$ sebagai suatu rujukan yang menggambarkan hubungan atau identitas sosial antarpenutur yang menggambarkan peran sosial yang mereka miliki. Jadi, dapat disimpulkan BS merupakan suatu unsur kalimat yang digunakan untuk menarik perhatian lawan bicara dan mencerminkan hubungan sosial, sikap personal penutur dan petutur. BS ini dapat bersifat vokatif dalam struktur kalimat dan deiksis sosial dalam wacana tutur.

BS dapat hadir di awal kalimat, di tengah, ataupun di akhir kalimat. Hal ini dapat dilihat pada tiga contoh berikut:

- George, I think it won't work.

- That's, my friends, what I call 'heaven's on fire'.

- I don't think I follow you, George.

Apabila posisinya ditengah BS berbentuk apositif seperti pada contoh. Dari ketiga contoh di atas juga terlihat secara sintaksis BS bukan berupa subjek atau objek kalimat karena menurut Crystal (1997) BS adalah suatu unsur kalimat yang kehadirannya boleh ada atau tidak dalam kalimat karena kehadirannya tidak mengubah konstruksi kalimat dan bukan unsur struktur klausa seperti subjek, objek, atau verba. Kehadirannya dalam kalimat dapat juga berfungsi mirip penyeru atau interjeksi yang bertujuan menarik perhatian orang yang diajak bicara. Perhatikan contoh berikut:

\section{Sir! You've left your bag!}

BS dapat muncul sebagai bagian kalimat yang terikat secara sintaktis yang dapat menempati posisi sebagai subjek atau objek (misalnya Does Madam wish to change her style? Sebagai strategi penghormatan) dan tidak terikat secara sintaktis (misalnya John, please help me with my laundry atau Please help me with my laundry, John).

Seseorang dapat disapa dengan berbagai jenis bentuk BS seperti yang diajukan oleh Quirk et al (1975; 773-775) dan Crystal (2003; 220) serta Yang (2010) yaitu:

1. Nama yang dapat berupa nama pertama atau first name (FN), nama akhir atau last name (LN), nama lengkap, dan nama panggilan diminutif (pengecil) seperti Danny untuk Daniel;

2. Penamaan standar yang mencakup hubungan kekerabatan (mommy, auntie), gelar penghormatan (ma'am, madam, sir, Your Honor, Your Excellency, Your Majesty), dan penanda status atau posisi (Mr. President, Prime Minister, Father (pendeta), professor, Chief, general)

3. Jenis pekerjaan, misalnya waiter, bartender, driver, nurse.

4. Panggilan yang bersifat evaluatif, baik yang bersifat menyenangkan (seperti dear, sweetheart) maupun ofensif (seperti idiot, bastard, faggot).

5. Nomina umum yang memiliki makna khusus seperti brother, buddy, man, ladies and gentlemen.

6. Pronomina persona you.

Ervin-Tripp (1972) mengajukan bahwa pada dasarnya dalam sistem sapaan masyarakat Amerika terdapat 7 jenis yaitu Gelar+LN (Last Name atau nama akhir), 
Mr+LN, Mrs+LN, Miss+LN, FN (First Name atau Nama Pertama), Gelar kekerabatan+FN, dan $\varnothing$ (tidak menggunakan BS sama sekali). Sistem sapaan merupakan seperangkat ekspresi linguistik yang membentuk suatu kesatuan kerja yang memperhitungkan berbagai faktor di luar bahasa yang menentukan apakah suatu ungkapan atau ekspresi berterima apabila digunakan dalam suatu situasi tutur. Ia mengajukan teori sistem sapaan Amerika yang ia sebut sebagai Alternative Co-occurence yang menyatakan bahwa dalam kaidah sosiolinguistik terdapat alternasi pilihan cara berbicara dan terdapat kehadiran bersama (kookurensi) adanya alternasi cara bertutur yang menyangkut jangkauan (range) pemilihan bahasa atau variasi bahasa yang dikuasai seorang penutur (linguistic repertoir) yang dipengaruhi oleh faktor mode, field, dan tenor. Faktor yang mempengaruhi penggunaan BS adalah situasi (formal-tidak formal), usia, jender, hubungan kekerabatan, perbedaan kuasa (power), jarak sosial, dan diketahui-tidaknya nama pesapa (Ervin-Tripp, 1972: 213).

Dari semua penelitian yang telah dilakukan, belum ditemukan adanya penelitian yang secara khusus membahas tujuan pemakaian BS dalam peristiwa tutur. Penelitian yang ada membahas jenis dan bentuk BS serta kapan BS digunakan sedangkan pada dasarnya BS memiliki makna yang lebih dari sekedar masalah kesantunan atau tepat-tidaknya sebuah sapaan. Penggunaan dan fungsi BS ini tentu berkaitan erat dengan masalah perbedaan kuasa, jarak sosial, dan tingkat imposisi.

\section{METODE PENELITIAN}

Metode penelitian yang digunakan pada penulisan ini adalah metode deskriptif kualitatif dengan menganalisis data yang diperoleh dari 8 film berbahasa Inggris Amerika. Penelitian dilakukan untuk menemukan fungsi BS sebagai strategi diskursif dalam percakapan. Data diambil dengan metode simak-catat lalu dipadankan dengan variabel sosial dan kontekstual sebagai unsur luar bahasa untuk menemukan fungsi BS sebagai strategi tutur. Data diambil dari sumber data yang berupa film-film produksi Amerika yaitu A Few Good Men (Castle Rock Entertainment, 1992), Patch Adams (Universal Pictures, 1998), American Beauty (DreamWorks Picture, 1999), Erin Brockovitch (Paramount Picture, 2000), Crash (Lion Gate Films, 2006), Freedom Writers (Paramount Pictures, 2007), Jarhead (Universal Pictures, 2007) dan Litle Miss Sunshine (Big Beach, Bona Fide Productions, 2006). Data yang berhasil dikumpulkan berjumlah 128 data yang berupa BS yang digunakan dalam interaksi verbal. Selanjutnya data diklasifikasi dan dianalisis berdasarkan fungsinya dalam percakapan dan hubungan para penggunanya berdasarkan variabel kuasa, solidaritas, dan tingkat mitigasi. Sebanyak 14 data digunakan sebagai sample dalam penelitian ini.

\section{HASIL DAN PEMBAHASAN}

Berdasarkan analisis data, ditemukan bahwa BS bahasa Inggris memiliki beberapa fungsi baik itu bersifat normatif dan strategi diskursif dalam percakapan. Fungsi yang bersifat normatif artinya BS yang digunakan merupakan sesuatu yang wajib digunakan dan bahkan diatur oleh hukum maupun perundangan dan norma yang berlaku dalam suatu organisasi. Fungsi diskursif BS bahasa Inggris Amerika yang ditemukan dalam data adalah: 


\section{Memenuhi aturan dan norma baku secara hukum}

Sidang di pengadilan merupakan sebuah peristiwa atau acara yang sudah terkodifikasi dan dibakukan yang artinya urutan prosesnya, tingkah laku, dan peran pesertanya sudah ditentukan atau ditetapkan secara jelas secara hukum dan memiliki keabsahan dalam proses hukum. Berdasarkan peran dan aturan hukum pulalah para partisipan menggunakan BS yang dibakukan. Hakim yang memimpin sidang menempati peran istimewa yang mewakili negara atau pemerintah dan menjadi lambang supremasi hukum yang harus dihormati. Bentuk interaksi verbal dengan hakim pun ditandai oleh keharusan menggunakan kalimat yang baku dan santun apabila tidak ingin terkena penghinaan atas pengadilan atau court contempt. Sapaan baku bagi hakim dalam sidang Amerika adalah Your Honor atau 'yang mulia' dan diacu juga dengan sapaan sir bagi pria dan ma'am bagi wanita, sedangkan jaksa dan pengacara diacu dengan counselor. Baik hakim maupun jaksa dan pengacara biasa diacu dengan gelar + LN. Hal ini ditemukan pada data:

Kaffee : The defense didn't have an opportunity to depose this witness, your honor. I'd ask the Court for a little latitude.

(A Few Good Men)

\section{Memenuhi aturan dan norma organisasional}

Organisasi militer merupakan contoh bagaimana terdapat suatu aturan atau norma menyapa. Sebagai suatu organisasi yang sangat hirarkis dan terorganisir, BS sangat dipengaruhi oleh perbedayaan kuasa yang berupa pangkat dan jabatan. Dalam peristiwa tindak tutur formal maupun informal nampak sekali sifat hirarkis organisasi ini yang ditunjukan oleh penggunaan BS berupa pangkat, jabatan, maupun nomina penghormatan sir atau ma'am. Henley (1995) dalam Jay (2000:163) menyatakan bahwa kuasa memberikan semacam hak istimewa kepada seorang penutur untuk melakukan hal yang tidak dapat dilakukan oleh mereka yang tidak memiliki kuasa yang sama atau lebih kecil dan dominansi memungkinkan invasi atas ruang pribadi, menyentuh orang lain, melakukan kontak pandang, dan menyapa bawahan dengan nama panggilan atau personal bukan gelar. Selain itu, dalam organisasi militer adanya jarak sosial ditunjukan dengan pemanggilan LN dan bukan FN, seperti pada contoh data berikut yang menceritakan seorang tentara, Anthony Swofford (AS), berinteraksi dengan Drill Sergeant Fitz (DSF) dalam suatu inspeksi barak:

$$
\begin{array}{ll}
\text { DSF } & \text { : Swofford! } \\
\text { AS } & \text { :Sir, yes, Sir! } \\
\text { DSF } & \text { : You're the maggot whose father served in Vietnam? } \\
\text { AS } & : \text { Sir, yes, Sir! }
\end{array}
$$

Data menunjukan bagaimana Swofford menyapa sang sersan dengan Sir secara konsisten sepanjang fim untuk menunjukan norma organisasi yang menunjukan perbedaan kuasa yang berupa perbedaan pangkat dan jabatan. Selain 
itu atasan secara konsisten menggunakan panggilan LN bagi bawahannya sepanjang film.

\section{Menunjukan kesantunan dan ketidaksantunan}

Kesantunan berarti menghargai perasaan orang lain atau menghormati wajah atau face yang ditampilkan oleh seseorang. Kesantunan secara linguistik berarti bertutur dengan orang lain sesuai dengan hubungan yang dimiliki oleh penutur dan petutur dengan memperhatikan unsur jarak sosial dan kuasa. Bentuk perbedaan jarak sosial dan kuasa ini dapat meliputi variabel usia, jender, status sosial, dan hubungan kekerabatan. Kesantunan juga ditentukan oleh peran dan jenis interaksi sosial yang terjadi misalnya kesantunan yang harus ditunjukan oleh seorang penjaga toko kepada pengunjung toko, murid kepada guru, maupun orang yang lebih muda kepada mereka yang lebih tua. Penunjukan kesantunan yang umum adalah menggunakan gelar + LN (misalnya Mr. Greenberg) dan pekerjaan atau jabatan + LN (misalnya Dean Walcott). Strategi diskursif menunjukan kesantunan ini dapat dilihat pada contoh data yang menggambarkan Erin, seorang pegawai, yang berbicara kepada atasannya, Ed Masry:

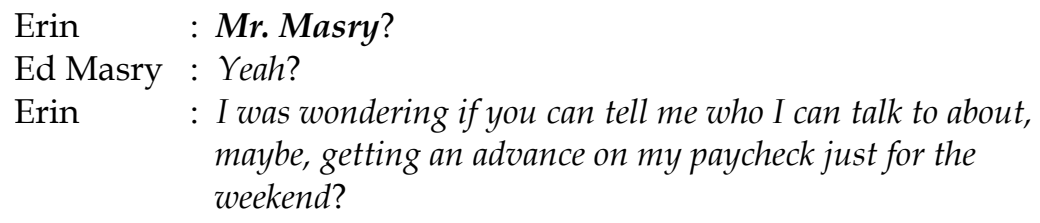
maybe, getting an advance on my paycheck just for the weekend?

(Erin Brockovich)

Sebagai pegawai yang sedang membutuhkan bantuan, Erin menggunakan strategi kesantunan berupa menyapa atasannya, Ed Masry, dengan BS gelar+LN sebagai upaya mitigasi permintaan yang membebani (imposisi). Hal yang menarik adalah ditemukannya data yang menunjukan bahwa kesantunan berbahasa Inggris Amerika dapat juga berupa mengganti pronomina indeksikal you dengan nama petutur seperti pada data berikut yang mana terjadi saat prajurit Anthony Swofford (SA) berinteraksi dengan atasannya drill sergeant Fitz (DSF) dalam suatu inspeksi:

$\begin{array}{ll}\text { DSF } & \text { : Are you eyeballing me with those baby blues, Swofford? } \\ \text { AS } & \text { : Sir, no, Sir! } \\ \text { DSF } & \text { : Are you in love with me, Swofford? } \\ \text { AS } & \text { : Sir, no, Sir! } \\ \text { DSF } & \text { : Oh, you don't think I look good in my uniform, Swofford? } \\ \text { AS } & \text { : Sir, the Drill Sergeant looks fabulous in his uniform, sir! }\end{array}$

Pada data ini AS mengacu atasannya saat memberikan reaksi atas pertanyaan DSF dengan bentuk indeksikal orang ketiga tunggal "Sir, the Drill Sergeant looks fabulous in his uniform" dan bukan "you look fabulous in your uniform" meskipun ia bersemuka langsung dengan DSF yang diacunya. Hal ini merupakan bentuk penghormatan (deference) yang tinggi seperti yang ditunjukan seseorang saat berbicara dengan seorang ratu, "Does Her Majesty wish to depart now?" (lihat Wales, 1996). 
Ungkapan yang bersifat ofensif atau disfemistik digunakan sebagai strategi diskursif yang menyatakan ofensivitas penggunanya yang melanggar ketidaksantunan. Bentuk disfemistik ini beragam bentuk dan maknanya, dari yang berhubungan dengan skatologi, kecacatan, sebutan rasial hingga seksualitas, seperti pada contoh yang ditemukan pada data:

\section{Get up, bitch!}

(Freedom Writer)

BS bitch jelas merupakan cara merujuk seseorang yang bersifat ofensif dan sebuah pilihan yang sengaja untuk menunjukan agresivitas karena makna kata tersebut yang ofensif bila digunakan untuk menggambarkan seseorang.

\section{Refleksi evaluatif personal atas jarak sosial dan solidaritas}

Jarak sosial atau solidaritas atau keakraban adalah sesuatu yang sulit diukur secara pasti. Hal tersebut lebih bersifat evaluatif dan subjektif. Nilai solidaritas ini dapat dibentuk oleh faktor-faktor seperti persamaan nasib atau kesamaan sosial, kekerapan bertemu, lama perkenalan, keakraban, rasa kesamaan pola pikir, dan perasaan positif atau negatif (suka-tidak suka) (Spencer-Oatey, 1996). Karena kedekatan atau keakraban ini cenderung berdasarkan sikap evaluatif individu, seberapa dekat seseorang dengan yang lainnya dapat dilihat salah satunya dari caranya menyapa.sikap evaluatif yang menyatakan kedekatan ini dapat dilihat dengan strategi diskursif penggunakan BS.

BS yang menunjukan adanya kedekatan atau sikap positif ditunjukan dengan penggunaan BS yang berupa nomina bermakna khusus seperti precious, hon/honey, dear, sweetie, darling, pretty atau nomina yang berupa makanan seperti cupcake, pumpkin, sugar, atau cutie pie yang menyiratkan rasa manis. Startegi ini ditemukan pada salah satu data seperti:

Sweetie, please don't get sick on me.

(Erin Brockovitch)

Selain nomina bermakna khusus, BS yang digunakan sebagai strategi kedekatan adalah penggunaan apelatif atau penamaan berupa FN yang dapat bersifat standar dan diminutif. Apelatif standar maksudnya tidak ada modifikasi FN seperti pada Emily, Mary, atau juga pemendekan nama seperti Patrick menjadi 'Pat' atau Daniel menjadi 'Danny'. Apelatif diminutif adalah penamaan dengan sufiks -ie atau bunyi [I] seperti Matt menjadi 'Mattie' atau Jane menjadi 'Janey'.

Sikap evaluatif negatif dapat ditunjukan dengan strategi menggunakan BS yang bermakna netral dan bersifat ofensif atau disfemistik sebagai ekspresi ketidaksukaan atau strategi menghina. Nomina yang bersifat netral dapat digunakan sebagai strategi penunjukan sikap bermusuhan seperti pada data yang mana diujarkan oleh seorang istri yang marah kepada suaminya:

Don't mess with me, mister, or I will divorce you so fast it'll make your head spin!

(American Beauty) 
Data ini menunjukan strategi penggunaan BS mister digunakan sebagai penanda bahwa kedekatan yang ada telah menghilang. Selain itu pada konteks tertentu nomina yang menyatakan rasa sayang dapat digunakan sebagai strategi diskursif sinisme seperti pada contoh data yang mana seorang wanita bernama Erin terpaksa kembali menegur tetangga barunya yang menghidupkan motor dengan kencang:

Are you getting every word of this, honey, or am I talking too fast for you?

(Erin Brockovitch)

BS honey mengindikasikan kondisi kontra-faktual karena pada kenyataannya penutur dan petutur tidak dekat dan baru saja bersemuka. Dapat disimpulkan bahwa konteks tindak tutur amat menentukan makna evaluatif sebuah BS.

\section{Menunjukan hubungan kekerabatan}

Penggunaan BS yang menyatakan hubungan kekerabatan ditemukan pada banyak data. Umumnya penggunaan BS jenis ini berkisar antara hubungan keluarga seperti kakek, nenek, ayah, ibu, paman, dan bibi.

Strategi penggunaan BS ang menyatakan hubungan kekerabatan ini menjadi penting saat dalam sumber data ditemukan bahwa terdapat kasus anak yang tidak menyapa orangtua biologisnya dengan BS mom atau dad sebagai strategi menunjukan rasa marah atau kecewa ketika orang tua tersebut tidak berfungsi sebagai orang tua yaitu mengurus dan membesarkan sang anak sehingga, alih-alih memanggilnya dengan mom atau dad, beberapa tokoh dalam sumber data menggunakan FN ketika bertemu orang tua biologisnya ketika dewasa.

\section{Penanda solidaritas dalam suatu kelompok sosial}

Setiap kelompok sosial atau komunitas sangat mungkin memiliki norma atau kebiasaan yang berbeda-beda satu dan lainnya. Hal ini tentu dapat menyebabkan interaksi verbal yang juga berbeda. Berdasarkan data yang dikumpulkan, penanda solidaritas dapat berupa penggunaan BS yang berupa LN dan ungkapan yang disfemistik.

Wardaugh (2014) menyatakan bahwa ada komunitas atau organisasi yang dalam interaksi verbalnya menggunakan BS berupa LN. Pada data yang dikumpulkan, penggunaan LN sebagai BS ditemukan pada institusi seperti lingkungan militer dan kepolisian hingga lingkungan sekolah berupa klub olahraga yang mana sang pelatih mengacu para atletnya dengan LN. Nampaknya hal ini merupakan sebuah strategi pemberjarakan (distance strategy) karena penggunaan FN dianggap sebagai hal yang lebih akrab daripada LN.

Selain penggunaan LN, penanda solidaritas berupa BS dapat berupa penggunaan ungkapan yang bersifat disfemistik seperti pada data:

Hey you all horny fucks, wanna see a beautiful woman?

(Jarhead)

Ketika seorang prajurit menunjukan foto kekasihnya kepada rekan-rekannya. Apte (2001) menyatakan bahwa penggunaan kata-kata tabu yang terus-menerus dapat menurunkan tingkat ketabuan kata-kata tersebut dan seseorang yang terusmenerus menggunakan menggunakannya dapat menjadi insensitif terhadap nilai 
ketabuan kata-kata yang digunakannya. Seorang antropologis, W.W. Picher, pada tahun 1972 meneliti komunitas pekerja lepas pantai di kota Portland, Oregon, USA, dan menemukan bahwa terdapat frekuensi pengunaan umpatan saat mereka bekerja di atas galangan kapal karena pekerjaannya bersifat berbahaya dan menyebabkan stress. Hal tersebut mereka lakukan sebagai suatu penyaluran rasa marah dan frustasi dan mereka berhati-hati menghindarkan penggunaan umpatan dalam lingkungan keluarga (Apte, 2001: 286). Nampaknya bentuk disfemistik yang digunakan sebagai BS merupakan salah satu cara untuk menyalurkan rasa tertekan dan sekaligus penanda keakraban dan juga sebagai penanda maskulinitas atau machismo (Holmes, 2012).

\section{Tujuan humoristik}

BS dapat digunakan sebagai unsur humor terutama apabila hubungan penyapa dan pesapa dekat. BS yang digunakan dengan tujuan humor biasanya berkenaan dengan evaluasi penyapa terhadap apa yang tengah dilakukan pesapa. Misalkan X dan $\mathrm{Y}$ adalah teman satu apartemen dan $\mathrm{Y}$ adalah seseorang yang pemalas. $X$ dapat menggodanya dengan "Would Your Highness care for some more coffee?" untuk menyindir Y yang misalnya meletakkan gelas kopinya yang telah kosong secara sembarangan. Sapaan Your Highness atau 'Yang Mulia' tentu dimaksudkan mengacu pada prilaku Y yang dianggap bertingkah seperti seorang raja yang tidak mau membereskan gelas kopi kotornya. Strategi humor ini juga ditemukan pada data ketika Daniel Kaffee (DK) yang mengenakan seragam upacara korps Angkatan Laut AS menghampiri Luther (L), seorang penjual koran langganannya:

\section{DK : Hey Luther.}

$\mathrm{L}$ : Admiral, how's the big case going?

(A Few Good Men)

Tentu saja diasumsikan Luther tahu Daniel Kaffee tidak memiliki pangkat tertinggi AL Amerika atau admiral dan BS digunakan oleh Luther sebagai strategi humor yang sifatnya berlawanan dengan kenyataan.

\section{Menunjukan sifat formal-tidaknya pembicaraan}

Dalam berinteraksi secara verbal, seorang penutur dapat mengirimkan penanda kepada pesapanya mengenai sikap evaluatifnya terhadap sang petutur atau jenis percakapan yang tengah berlangsung. Perbedaan kuasa menyebabkan seseorang yang memiliki kuasa yang lebih besar memiliki kemampuan untuk menentukan pola interaksi verbal yang dinginkannya. Hal ini dapat dilihat pada contoh data ketika Dekan Sekolah Kedokteran, Dean Walcott (DW), memanggil Hunter Adams (HA) yang biasa dipanggil 'Patch' oleh teman-temannya untuk membahas masalah prestasi Hunter Adams:

DW : I've checked up on you, Hunter.

HA : Patch. Call me 'Patch'.

DW : Hunter, Dr. Prack was a colleague of mine at Birmingham. He tells me you 
have a brilliant mind and like many brillian people you don't necessarily think the rules apply to you.

HA : Not all the rules, sir, but the golden rule. I think that applies to us all.

DW :Mr. Adams, when I told you I knew Dr. Prack, did I mislead you in some ways to think that I'm a pushover like he is?

(Patch Adams)

Dari kutipan data ini, dapat dilihat bahwa DW dengan sengaja menolak menunjukan adanya solidaritas dengan menolak memanggil HA dengan nama 'Patch' dan menyapanya dengan LN (Hunter) hingga akhirnya DW pun menggunakan BS berupa gelar+LN untuk menunjukan jarak sosial yang semakin jauh dan sifat percakapan yang bersifat formal dengan penggunaan BS tersebut. Ini artinya BS dapat digunakan sebagai suatu strategi diskursif yang menandai sifat sebuah interaksi verbal.

\section{Merujuk pada hubungan kuasa penyapa-pesapa}

Dalam percakapan seorang penutur dapat menggunakan beragam cara untuk mencapai apa yang diinginkannya dengan bercakap. Dalam interaksi verbal, BS dapat digunakan sebagai sebuah strategi penegas hubungan kuasa antara penutur dan petutur agar misalnya petutur menuruti kehendak penutur. Data ini didapatkan ketika dalam sumber data Kolonel Nathan E. Jessup memanggil bawahannya Letnan Kolonel Matthew Markinson yang telah memprotes keputusan Jessup. Jessup dan Markinson merupakan teman sekelas di akademi militer namun Jessup memiliki kenaikan karir yang lebih cepat daripada Markinson sehingga ia menjadi atasan langsung Markinson:

Sit down, Matthew. We go back awhile. We went to the academy together. We were commisioned together. We did our tours in Vietnam together. But I've been promoted up through the chain with greater speed and success than you have. Now if that's a source of tension or embarassment, I don't give a shit. We're on the business of saving lives here, Lieutenant Colonel Markinson. Don't ever question my orders in front of another officer.

(A Few Good Men)

Pada data ini Jessup menggunakan alternasi BS terhadap Markinson saat ia menyatakan kemarahannya atas perbuatan Markinson yang telah mempertanyakan keputusannya sebagai seorang atasan langsung Markinson. Awalnya Jessup menggunakan BS berupa FN 'Matthew' yang nampaknya wajar karena mereka adalah kawan sekelas dan seperjuangan, baik itu di akademi militer maupun dalam ekspedisi militer, namun ia kemudian menggunakan BS berupa pangkat+LN sebagai strategi diskursif untuk mengingatkan Markinson bahwa ia seorang letnan kolonel yang satu tingkat lebih rendah dari Jessup yang berpangkat kolonel. Dalam data ini nampak perubahan dari sapaan kasual menjadi sapaan formal dan standar yang menandai hilangnya kedekatan atau solidaritas. Tentu saja strategi ini dapat berlaku apabila terdapat perbedaan kuasa antara penutur dan petutur.

\section{Menunjukan ekspresi mitigatif}

Mitigasi secara pragmatik berarti 'meringankan' dan biasanya perangkat mitigasi (mitigating devicei) digunakan untuk memperlunak permintaan atau imposisi (lihat Grundy (2000) dan Bonvillain (2003)). Penggunaan BS digunakan 
sebagai ekspresi mitigasi yang menyatakan kedekatan atau perasaan senasib. Hal ini dapat dilihat pada data yang mana seorang polisi, Ryan (R), yang memberi tumpangan kepada seorang pemuda (P) yang menyetopnya kala ia berkendara. Tanpa alasan yang jelas $\mathrm{P}$ tertawa dan hal ini menyebabkan ketidaknyaman pada R: Something else funny?

P: Yeah, people, man.

$\mathrm{R}:$ Are you laughing at me?

P: No, no, no, I'm not laughing at you, man.

Come on, man! Keep driving. I said I'm not laughing at you.

$\mathrm{P}$ berusaha agar $\mathrm{R}$ tidak tersinggung dan menggunakan BS yang menandakan akraban man. Hal ini dapat dilihat sebagai upaya P untuk meredakan ketersinggungan $\mathrm{R}$ dengan menggunakan sapaan man yang menunjukan rasa solidaritas.

Selain itu, pada latar keluarga, BS dapat digunakan untuk melunakkan sebuah permintaan seperti pada data yang mana seorang suami meminta pengertian istrinya agar dapat membereskan urusan kantornya saat acara keluarga. Sang suami mengujarkan:

Aw, come on, honey, it only takes a minute of our family time!

(Little Miss Sunshine)

BS honey yang menyatakan kedekatan digunakan agar sang istri mau mengerti dan memberikan ijin kepada suaminya agar dapat bekerja saat ada acara keluarga. BS yang digunakan menyiratkan adanya rasa sayang dan melunakkan permintaan yang tentunya tidak disetujui oleh sang istri. Berdasarkan data dapat disimpulkan bahwa strategi solidaritas dapat digunakan untuk memperingan suatu tindakan yang membebani.

\section{PENUTUP}

Berdasarkan analisis data didapatkan simpulan bahwa BS bahasa Inggris Amerika tidak semata-mata memiliki fungsi indeksikal yang merujuk petutur atau lawan bicara saja. Penelitian ini menemukan bahwa BS dapat memiliki fungsi strategi diskursif yaitu suatu upaya untuk memenuhi tujuan diadakannya percakapan. Terdapat 10 fungsi BS yang ditemukan dalam data yaitu sebagai: pemenuhan aturan dan norma baku secara hukum, pematuhan aturan dan norma organisasional, penunjukan kesantunan, refleksi evaluatif personal atas jarak sosial dan solidaritas, penunjukan hubungan kekerabatan, penanda solidaritas dalam suatu kelompok sosial, strategi humoristik, penanda sifat formal-tidaknya pembicaraan, perujuk hubungan kuasa penyapa-pesapa, dan ekspresi mitigatif. Penelitian lebih lanjut dapat dilakukan misalnya dengan meneliti BS ini dari segi linguistik kognitif misalnya. 


\section{DAFTAR PUSTAKA}

Apte, M.L. 2001. Taboo Words, dalam Concise Encyclopedia of Sociolinguistics, Rajend Mesthrie (ed). UK: Elsevier Science Ltd.

Bonvillain, Nancy. 2003. Language, Culture, and Communication, edisi keempat. New Jersey: Upper Saddle River

Cruise, Alan. 2000. Meaning in Language. New York: Oxford University Press

Crystal, David. 1997. Cambridge Encyclopedia of the Language. Cambridge: Cambridge University Press

Crystal, David. 2003. The Cambridge Encyclopedia of the English Language.Cambridge: Cambridge University Press

Ervin-Tripp, Susan. 1972. On Sociolinguistic Rules: Alternation and Co-occurrence. dalam Directions in Sociolinguistics (Gumperz, John J. \& Hymes, Dell (ed)), USA: Holt, Rinehart, and Winston, Inc.

Holmes, Janet. 2013. An Introduction to Sociolinguistics. Edisi keempat. New York: Routledge

Jay, Timothy. 2000. Why We Curse: USA: John Benjamin B.V.

Levinson, Stephen C. 1999. Deixis, dalam Concise Encyclopedia of Grammatical Categories Brown, Keith et al (ed.). Oxford: Elsevier Science Ltd.

McArthur, Tom (ed.). 2005. Concise Oxford Companion to the English Language,USA: Oxford University Press

Spenser-Oatey, Hellen. 1996. Reconsidering Power and Distance. Journal of Pragmatics Volume 26, Issue 1. Elsevier B.V.

Quirk, Randolph, et al. 1985. A Comprehensive Grammar of the English Language: USA: Longman Group UK Limited

Wales, Katie. 1996. Personal Pronouns in Present-Day English. Cambridge: Cambridge University Press

Wardhaugh, Ronald. 2014. Introduction to Sociolinguistics, edisi kelima. Oxford: Blackwell Publishers Ltd.

Yang, Xiaomei. 2010. Address Forms of English: Rules and Variations. Journal of Language Teaching and Research, Vol. 1, No. 5. 